
\title{
25 Research Soure \\ Impact of the COVID-19 pandemic on stress and emotional reactions in Israel: A mixed-methods study
}

Inbar Levkovich ( $\square$ Inbar.lev2@gmail.com )

Oranim Academic College https://orcid.org/0000-0003-1582-3889

Shiri Shinan-Altman

Bar-llan University

\section{Research}

Keywords: COVID-19, Emotional reactions, Perceived susceptibility, Israel, Mixed-methods

Posted Date: May 27th, 2020

DOI: https://doi.org/10.21203/rs.3.rs-30346/v1

License: (c) (1) This work is licensed under a Creative Commons Attribution 4.0 International License.

Read Full License

Version of Record: A version of this preprint was published at International Health on October 13th, 2020. See the published version at https://doi.org/10.1093/inthealth/ihaa081. 


\section{Abstract \\ Objectives}

The COVID-19 pandemic has had a profound impact on the public worldwide. This exploratory study sought to identify the pandemic's psychological impact on the Israeli public using a mixed-methods approach.

\section{Methods}

During the COVID-19 outbreak, Israeli adults $(N=1,407)$ completed a battery of measures assessing psychological variables and perceived threat related to COVID-19. Statistical analyses included tests for between-group differences and Pearson correlations. Qualitative, in-depth, semi-structured interviews $(\mathrm{N}=$ 38) were conducted.

\section{Results}

The findings of the quantitative study indicate that about half of the public were concerned, afraid and stressed and a fifth perceived they were liable to contract the virus. Moreover, a positive correlation emerged between these feelings and degree of perceived threat. Three major themes emerged from the qualitative study: 1 ) a sense of shock and chaos; 2 ) gradual adjustment to the new reality; 3) fears and concerns for self and family members.

\section{Conclusions}

The study provides a comprehensive picture of psychological variables and perceived threat related to COVID-19 in Israel. Social distancing is likely to make people feel safer but also to increase their feelings of isolation, stress and frustration and to cause difficulties in many life situations. The findings indicate that the public's perceived susceptibility and emotional reactions about the COVID-19 should be addressed.

\section{Introduction}

The coronavirus disease 2019 (COVID-19) pandemic is a global health crisis of massive proportions. As a result of this outbreak, citizens across the globe must cope with new emotional challenges and particularly with feelings of stress, uncertainty and fear. COVID-19 poses a real threat to physical and emotional health [1]. Indeed, previous research on viruses revealed that such situations exert an emotional impact on the stress and resilience levels of individuals around the world [2]. Psychological effects may be caused by individuals' fear of becoming ill themselves, fear that those close to them will become ill or fear of dying. Feelings of fear and helplessness together with reports of shortages in 
medical supplies in the current epidemic are liable to increase stress [3]. During an outbreak of flu, for example, about $10-30 \%$ of the general public reported major fears of contracting the disease [4]. When schools and shops were closed during the SARS outbreak, people reported an increase in negative emotions, and the level of psychiatric morbidity also increased [5]. Women, older adults, educated individuals, anxious individuals and those who had symptoms of the virus were more meticulous in complying with precautionary measures against the virus [6, 7]. Moreover, research that examined emotional responses to the Ebola virus pointed to depression, anxiety, difficulties in concentration and a sense of grief [8].

A study of COVID-19 conducted in China found that among 1210 respondents from the general public, $53.8 \%$ rated the psychological impact of the outbreak as moderate or severe, $16.5 \%$ reported moderate to severe depressive symptoms, $28.8 \%$ reported moderate to severe anxiety symptoms and $8.1 \%$ reported moderate to severe stress levels [9]. Another study that examined 52,730 participants in Hong Kong found that $35 \%$ reported feeling of stress from COVID-19, with women reporting higher levels of stress than men [1].

The first Israeli with COVID-19 was diagnosed toward the end of February 2020. Since then, thousands have been in isolation in their homes, 13,930 have been diagnosed with this virus and as of April 21, 2020, 181 have died from this virus [10].The Israel Ministry of Health has released and updated guidelines and instructions to explain the new daily routine to the general public (e.g., precautions such as frequently washing hands with soap and water or alcohol-based hand sanitizers, avoiding close contact with people showing symptoms, refraining from shaking hands and covering the mouth and nose when coughing or sneezing) [10]. The ongoing rise in the numbers of suspected and diagnosed cases may also affect the public's estimations of the severity and controllability of the virus [11-13].

Therefore, the current study used quantitative methods to examine the Israeli public's emotional reactions and perceived susceptibility to COVID-19. It then employed qualitative methods to investigate how the Israeli public perceived their experiences with the virus, how they expressed their emotions on this matter and how they perceived their own coping methods.

\section{Phase 1: Quantitative Study \\ Methods}

\section{Procedure and participants}

Prior to commencing the study, the researchers obtained authorization from the Ethics Committee at BarIlan University (Authorization No. 032003). The study is a cross-sectional online survey conducted among 1,407 participants in Israel (Table 1). To minimize personal contact during the outbreak, the questionnaires were administered online through the Qualtrics online platform (www.qualtrics.com) between March 12 and March 21, 2020. Inclusion criteria for the study were individuals aged $18+$ who 
were Hebrew speakers. Exclusion criteria were: under the age of 18, the cutoff age for requiring parental consent; responses conforming to a similar pattern (e.g., choosing the same answer across many consecutive items or for the entire questionnaire); failure to complete the entire questionnaire.

Table 1

Participants' demographic characteristics $(\mathrm{N}=38)$

\begin{tabular}{|lll|}
\hline Characteristic & N & \multicolumn{1}{c|}{$\%$} \\
\hline Age (mean and standard deviation; years) & $\mathrm{M}=33.26, \mathrm{SD}=10.15$ \\
\hline Number of children (mean and standard deviation) & $\mathrm{M}=1.29, \mathrm{SD}=1.4$ \\
\hline Sex & & \\
\hline Men & 9 & $23.7 \%$ \\
\hline Women & 29 & $76.3 \%$ \\
\hline Marital Status & & \\
\hline Married & 18 & $47.4 \%$ \\
\hline Single & 18 & $5.3 \%$ \\
\hline Divorced & 2 & $47.4 \%$ \\
\hline Occupation & & \\
\hline Student & 11 & $28.9 \%$ \\
\hline Salaried & 25 & $65.8 \%$ \\
\hline Self-employed & 2 & $5.3 \%$ \\
\hline
\end{tabular}

\section{Measures}

Perceived susceptibility was assessed based on previous studies conducted among the lay public (e.g., [14]) using a one-item measure to examine the participant's perceived likeliness of contracting the virus (e.g., "In your opinion, how likely is it that you will contract COVID-19?"). Answers were rated on a 5-point Likert-type scale ranging from $1=$ not at all likely to $5=$ very likely.

Emotional reactions to COVID-19 were assessed based on previous studies conducted among the lay public (e.g., [14]) using three questions relating to worry, fear and stress caused by COVID-19 (e.g., "How much do you worry about COVID-19?"). Answers were rated on a 5-point Likert-type scale, ranging from 1 $=$ not at all to $5=$ very much. A composite index of the averages of all items was created, with a higher score indicating higher levels of negative emotional reactions toward COVID-19. The internal consistency of the index was excellent (Cronbach's $a=0.94)$.

Socio-demographic variables included sex, age, years of education, marital status (married/divorced/widow/single/other), number of children, medical problems (yes/no), health status 
(poor/fair/good), home isolation since the COVID-19 outbreak (yes/no), resources that would make coping with COVID-19 easier (more information regarding COVID-19 / professional support / lay support / working from home / other).

\section{Statistical analyses}

The data were analyzed using SPSS ver. 25. Descriptive statistics were used to describe the participants' demographic characteristics and the research variables. Pearson correlations were calculated to assess the associations between the research variables.

\section{Phase 2: Qualitative Study Methods}

The study adopted a qualitative-phenomenological approach [15]. This type of approach attempts to obtain an in-depth understanding of the studied phenomenon by entering the world and experiences of the participants. Such a paradigm facilitates examining the voices and experiences of the informants as they choose to express them, thus providing a deeper understanding of the interviewees and arriving at insights that give meaning to multidimensional phenomena [16].

\section{Sample and Population}

The present study focused on a sample from the Israeli public ( $N=38 ; 29$ women and 9 men). Table 1 provides details pertaining to the sample's background characteristics. Participants ranged in age from 20 to $53(M=33.26, S D=10.15)$ and had 0 to 4 children $(M=1.29, S D=1.4) ; 47.4 \%$ were married, $47.4 \%$ were single and $5.3 \%$ were divorced.

\section{Procedure and Instrument}

The research instrument was a semi-structured, in-depth questionnaire. The interviewer encouraged participants to tell about their experiences in their own words. The interviews were conducted based on an interview guide (see Appendix 1 ) that included significant key areas, yet was flexible enough to allow both for the development of a dialogue between interviewer and interviewee and for meaningful selfexpression [17]. All interviews were conducted by telephone, audio-recorded and subsequently transcribed. Each interview lasted for half an hour. Data collection and analysis proceeded until theoretical saturation was reached (i.e., additional interviews yielded no new material for analysis).

\section{Data analysis}

The content analysis in this study included the following stages: 1) Open coding: The principal investigator first read each interview transcript line by line, jotting down notes to capture and identify initial units of meaning (categories) emerging from the data. 2) This researcher reviewed the major themes and discussed them with the other researcher. 3) Axial coding: Upon reading the transcripts a second time, the researchers gradually detected associations between themes and sub-themes related to 
context and content. They compared all completed interviews to consolidate meanings and arrive at a theoretical construct. 4) Integration: The core themes or main categories emerging from the data were reordered conceptually and placed back into context, making it possible to analyze and integrate large amounts of data and to generate abstractions and interpretations [16].

\section{Results}

\section{Quantitative phase results}

This study was a cross-sectional online survey conducted among 1,407 participants in Israel. The majority of the respondents were female ( $80 \%)$. The mean age of the participants was 41 years old (range 18-97) and they had an average of about 16.5 years of education (range 9-30). Most were married $(63 \%)$ and had an average of two children. About $85 \%$ reported having no health problems and about $80 \%$ reported their health status as good. Only $5 \%$ were isolated in their homes since the COVID-19 outbreak. Moreover, participants indicated that working from home was their preferred resource in coping with COVID-19. 
Table 2

Participants' characteristics $(\mathrm{N}=1,407)$

\begin{tabular}{|c|c|}
\hline Characteristic & $\mathbf{N}(\%)$ \\
\hline \multicolumn{2}{|l|}{ Gender (\%) } \\
\hline Male & $282(20.1)$ \\
\hline Female & 1119 (79.9) \\
\hline Mean age (SD), & 40.97 (14.66), \\
\hline range & $18-97$ \\
\hline Mean number of years of education (SD), & 16.44 (3.66), \\
\hline range & $9-30$ \\
\hline \multicolumn{2}{|l|}{ Marital status (\%) } \\
\hline Married & 879 (62.7) \\
\hline Divorced & $81(5.8)$ \\
\hline Widow & $24(1.7)$ \\
\hline Single & $380(27.1)$ \\
\hline Other & $37(2.6)$ \\
\hline Mean number of children (SD), range & 2.18 (1.39), $0-9$ \\
\hline \multicolumn{2}{|l|}{ Health problems (\%) } \\
\hline Yes & $214(15.3)$ \\
\hline No & $1186(84.7)$ \\
\hline \multicolumn{2}{|l|}{ Health status (\%) } \\
\hline Poor & 19 (1.4) \\
\hline Fair & 276 (19.6) \\
\hline Good & 1108 (79.0) \\
\hline \multicolumn{2}{|c|}{ Home isolation since the outbreak of the Covid-19 (\%) } \\
\hline Yes & $70(5.0)$ \\
\hline No & $1333(95.0)$ \\
\hline \multicolumn{2}{|c|}{ Resources that can make it easier to cope with COVID-19 (\%) } \\
\hline More information regarding COVID-19 & $260(19.4)$ \\
\hline Professional support & $172(12.8)$ \\
\hline
\end{tabular}




\begin{tabular}{|ll|}
\hline Characteristic & $\mathbf{N}(\%)$ \\
\hline Layman support & $143(10.7)$ \\
\hline Working from home & $529(39.4)$ \\
\hline Other & $237(17.7)$ \\
\hline
\end{tabular}

Table 3 summarizes the means, SDs, ranges and correlates of the study variables. As can be seen, the mean scores for emotional reactions $(M=2.72, S D=0.93$, range $1-5)$ and perceived susceptibility were high $(M=3.25, S D=1.14$, range $1-5)$. Positive associations were found between perceived susceptibility and emotional reactions to COVID-19 $(r=0.31, p<0.001)$. Moreover, perceived susceptibility exhibited a negative association with age, preexisting conditions and sex, indicating that those who were older, had more preexisting medical conditions and were male reported higher perceived susceptibility. Emotional responses exhibited a positive association to age and marital status and a negative association to sex, preexisting medical conditions and subjective perception of health status. Figure 1 shows that the participants reported the following emotional reactions: worry (48.5\%), fear (38.6\%), stress $(37.7 \%)$ and feeling they were likely to contract the disease (16.6\%). 
Table 3

Correlates, Means, SDs, and ranges of study variables $(n=1,407)$

\begin{tabular}{|c|c|c|c|c|c|c|c|}
\hline Variables & 1 & 2 & 3 & 4 & 5 & 6 & 7 \\
\hline 1.Age & - & & & & & & \\
\hline 2.Gender & $1.19 * \star \star$ & - & & & & & \\
\hline 3. Marital Status & $-.34^{\star \star}$ & $.06^{\star}$ & - & & & & \\
\hline 4. Preexisting conditions & $-.24 \star \star$ & .04 & -.02 & - & & & \\
\hline 5. Perceived health status & $-.12^{\star \star}$ & -.02 & $.43^{\star \star}$ & & - & & \\
\hline 6. Perceived susceptibility & $-.08 * \star$ & $-.19 * \star$ & -.003 & $-.06^{\star}$ & $-.18 \star \star$ & - & \\
\hline 7. Emotional reactions & $1.21^{\star \star}$ & $-.22 \star \star$ & $.09 * \star$ & $-.07 \star \star$ & $-.12^{\star \star}$ & $0.31^{\star \star \star}$ & - \\
\hline Mean & 40.84 & 1.8 & 1.77 & 1.85 & 2.78 & 2.72 & 3.25 \\
\hline SD & 14.78 & 0.40 & 1.08 & 0.36 & 0.45 & 0.93 & 1.14 \\
\hline Possible range & - & - & - & - & $1-3$ & $1-5$ & $1-5$ \\
\hline Actual range & $18-97$ & - & - & - & $1-3$ & $1-5$ & $1-5$ \\
\hline \multicolumn{8}{|l|}{$\star \star \star * p<0.001$} \\
\hline \multicolumn{8}{|c|}{ Preexisting conditions: yes/no } \\
\hline \multicolumn{8}{|c|}{ Perceived health status: good/fair/poor } \\
\hline
\end{tabular}

\section{Quantitative phase results}

The findings of the qualitative study yield three main themes: 1 ) a sense of shock and chaos; 2) gradual adjustment to the new reality; 3) fears and concerns for themselves and their loved ones.

\section{Theme 1 - "I'm losing control": Sense of shock and chaos}

The research participants described how their lives changed overnight. The change was drastic, surprising, powerful and difficult to contain. When the COVID-19 epidemic broke out in China, the participants felt the virus was far away and that they were immune from it. As the epidemic got closer, reaching European countries and Israel as well, the respondents' sense of shock and serious concern rose. People got their information from diverse media sources. Some of these sources were reliable, such as the Israeli Ministry of Health. Other less reliable sources spoke of conspiracy theories and a feeling that the world was coming to an end. Moreover, the guidelines provided by the Ministry of Health were not always clear to everyone, leading to confusion, information chaos and inner upheaval. 
COVID-19 made its surprising debut on the world stage only a few months ago, a short period that now feels like an eternity. Initially we asked, "What is this? How should we respond to this event?" We were confused, uncertain, aware that this is a major event, something new that we've never experienced. I felt a tremendous need to follow the news and learn what was happening in the world in order to dispel my sense of uncertainty, to understand the repercussions, to learn how this will affect us and understand how to behave. (47-year-old married man, 2 children).

Some of the participants indicated that their feelings ranged from a sense of indifference to denial of the situation and continuing their ordinary behavior. They then began to internalize the difficult situation as it filtered down to them. They were overcome by a sense of lack of control and helplessness that necessitated changes in their behavior.

I was overcome by tremendous fear due to COVID-19, fear of contracting the disease, fear of the new reality. I felt helpless and it's hard for me to function in this new reality that has been forced upon me. ... I thought the situation would pass quickly and I never thought it would reach such great proportions that the entire country would be shut down (26-year-old single woman).

Some of the participants described being shocked and confused. They searched for a direction to follow, wondered how they should behave and what they should do. The situation generated feelings of frustration and of being stuck.

Since the COVID-19 outbreak, I have been feeling very frustrated and overwhelmed. The spread of the virus put me in a state of shock, I didn't know how to digest this new reality that until now l've never had to face, how to respond to the situation as it is, how I should act. I didn't know how to divide up my time and what I should do. The virus put everything on hold for me. (53-year-old divorced woman, 3 children).

\section{Theme 2 - "Recalculating the route": Gradual adjustment to the new reality}

The participants indicated that after their initial feelings of shock, they found themselves gradually adjusting to the new reality that had been forced upon them by COVID-19 and the Ministry of Health guidelines. Adjustment difficulties stemmed from having to remain within their own household, limit their movements and, for some, stop working. The participants described how they internalized these guidelines and made changes in their familiar lifestyle.

As the situation developed and the virus began to spread, I saw how everything around me began to close and shut down... I began to think differently, to conduct myself differently, to leave the house less frequently, to pay much more attention to maintaining hygiene than usual, to keep my distance from people, to refrain from touching, even my own family. My life routine has changed. I leave the house only if I need something, groceries or the pharmacy or other urgent necessities (32-year-old married man, 1 child). 
The main issue that emerged among all the research participants who had children focused on how to maintain a daily routine. Before this happened, the children were at school, attended afterschool activities, met with friends. Now parents are charged with the difficult task of mediating this new situation for their children while at the same time maintaining a routine without any clear or defined framework.

One day, out of the blue, without any advanced warning or chance to prepare, I found myself in a new reality that forced me to recalculate my route, and fast. I found myself at home with my family and I had to be their anchor at a time when everything around us is unknown and uncertain. How can I manage under these circumstances? How can I explain this strange new reality to my children? How can I maintain some sort of sane schedule when everything is so unclear? Yet despite all these complexities, I understood that this is a good time and wonderful opportunity for a mother with a family. (42-year-old married woman, 3 children).

Some of the parents described how they are adjusting to the new situation by setting up a regular routine that includes chores, arts and crafts, cooking activities, home workouts and cleaning. Most of the children study via distance learning and many of the parents work from home. Many parents told about being exhausted by these diverse roles and by the physical and emotional burden they entail.

I found that the easiest way for us to cope with the isolation was to set up a regular daily routine. When this first began, we tidied up the house, set up an arts and crafts space on a large table and began designing a lovely family album with all the photos we developed from our last family vacation. This took us three whole days and we enjoyed working together on this project (31-year-old married woman, 2 children).

An important element in adjusting to this new situation is coping together as a couple. Members of a couple who are accustomed to working outside the home and seeing each other only several hours a day find themselves together for many hours. If one partner is not working, he or she may feel unneeded and useless. Such situations can lead to frustration and conflict between the partners and within the family. The family as a unit must adjust to the new reality.

It wasn't easy for me to see my husband at home, not working, depressed, incapable of doing the simplest everyday tasks. Unlike him, I gathered all my strength and tried to keep things running smoothly at home and not disrupt the normal routine (43-year-old married woman, 4 children).

The research participants also included young single people who were forced by the situation to return to their parents' home. These participants described how difficult this was, citing their feelings of having regressed by returning to live with their parents and siblings, a sense of having been robbed of their freedom. Yet the situation also provided an opportunity to renew their acquaintance and draw closer to their families.

Over the last two days the situation began to get worse. The entire family at home all the time is challenging and really difficult. We are all at different ages and stages, and each of us wants to do what 
we feel like doing. It's especially tough for me because before COVID-19 I was usually not at home. I was studying or at work or out with my girlfriends and suddenly I can't even leave the house. It drives me crazy (23-year-old single woman).

Theme 3 - "It's hard to fall asleep and even harder to get up in the morning": Fears and concerns for self and family

The research participants described their concerns about their own health and the health of their loved ones. Some mentioned that people close to them were under quarantine or tested positive for COVID-19, increasing their stress and sense of helplessness. They are flooded by worry due to the uncertainty about when this will end and what will happen to them and their loved ones.

There are moments of crisis. Especially at night. Sometimes I feel I'm on the brink of losing hope. I have trouble coping with the ambiguity and uncertainty about how long this crisis will last. There's no definitive time limit, and I wonder how long I'll be able to be strong. How will things be when this is all over? What about the children? How long can they hang on? What about my parents? When I finish my daily routine I am flooded with worries and have trouble falling asleep (43-year-old divorced woman, 4 children).

Many of the participants expressed concerns about older family members or those at risk due to preexisting medical conditions. They worried about their elderly parents and grandparents. These worries led to a sense of uncertainty about the future, anxiety and lack of control over the situation.

My grandmother is in a high-risk group. She must not leave the house and the grandchildren, including me, cannot visit her. At first I found it very difficult to discuss the situation with her. She continued going to the grocery store and following her regular routine. When all her activities closed down she understood that the situation is really problematic and dangerous for her. I try to speak to her as frequently as possible by phone and video calls with the other grandchildren. The situation is very worrisome and makes me sad, both the physical risk of the virus and the emotional toll, because she now feels more lonely than ever before. Not only will she feel alone, she'll also feel she's getting old, something she has always feared (24-year-old single woman).

Some of the participants described how their concerns and fears affect their behavior and emotions. They mentioned sleep disturbances, restlessness, irritability and difficulty performing tasks. They felt depressed, anxious, sad and lonely as well as nervous, uncertain and helpless.

During this period I have practically stopped functioning. I constantly worry about what the situation will be in a few more days and where I'll be and how I should behave during this period. Since the outbreak of the virus, every day I am more worried and concerned about my family, my friends, the entire world. I'm always anxious and am not functioning like I used to. I'm more irritable and I don't feel like talking to anyone. I'm a student and I can't concentrate on my studies or work from home. I am not functioning (28year-old single woman). 
Table 4

Classification of main categories and subcategories

\section{Main categories Subcategories}

$\begin{array}{ll}\begin{array}{l}\text { Sense of shock and } \\ \text { chaos }\end{array} & \cdot \text { Information search } \\ & \cdot \text { Sense of shock, confusion, frustration } \\ & \cdot \text { Sense of lack of control and helplessness regarding the need for } \\ \text { behavioral changes }\end{array}$

Gradual adjustment to the new reality
- Internalizing the guidelines and changing one's customary lifestyle

- Changes in the family - the children are at home

- Changes in the couple relationship - the members of the couple are together all the time; one or both may be unemployed

- Concerns for own health and health of those close to them

- Many described concerns for older relatives or those with illnesses in highrisk groups

- Concerns affect behavior: sleep disruptions, restlessness, irritability, difficulty performing tasks

- Depression, anxiety, sadness, loneliness alongside anxiety, uncertainty and helplessness

\section{Discussion}

The objective of the current study was to use a mixed-methods approach to examine the psychological responses to the COVID-19 outbreak among the Israeli public. The findings indicate that about half the public felt concern, fear and stress and a fifth believed they were liable to contract the virus. Moreover, a positive association emerged between emotional responses and extent of the perceived threat. The qualitative study expanded our understanding of the psychological process people underwent.

Participants described their sense of shock and chaos at the outbreak of the epidemic, followed by a gradual process of adjustment to the new situation along with fears and concerns for their own welfare and that of their loved ones.

The findings point to the presence of some degree of psychological distress among half the respondents which, if not properly managed, has the potential to progress. The development of mental health issues in the wake of life-threatening event has been demonstrated among survivors of the Ebola and SARS outbreaks, who exhibited stress, worry and PTSD symptoms $[18,19]$.

Since COVID-19 is a global threat, all the news and media channels provide continuous coverage of the epidemic, and specifically of the Ministry of Health's updated statistics and most recent guidelines [10]. Moreover, most people locked down in their homes watch the news nonstop and tend to panic about the rising numbers of infections and deaths $[20,21]$. Indeed, media exposure is another possible explanation 
for the high levels of stress and emotional response emerging in this study. The study was conducted about three months after the initial COVID-19 outbreak and a month after the crisis hit Israel. The Israeli public had already received health guidelines and information about the virus from the media. A study about the SARS outbreak indicates that the public's perceived threat is based more on rumors and unreliable sources than on information from the official health authorities [22]. A study on COVID-19 conducted in India found that media exposure increased the public's level of anxiety [23]. Evidence indicates that repeated engagement with trauma-related media content for several hours a day shortly after a collective trauma may prolong acute stress [24]. In the specific case of the COVID-19 outbreak, greater exposure to threat increases people's fears regarding the virus [25].

Likewise, societal safety measures (e.g., lockdowns) have their use in preventing the spread of infections. Yet when such safety measures are too prolonged or too strict, they can have negative consequences, among them economic disruption and unemployment [21]. Social distancing that includes closing shops and schools and working from home is likely to make people feel safer but also to increase their feelings of isolation, stress and frustration and to cause difficulties in many life situations (in the family, between members of a couple, in the employment sphere) [26].

The qualitative study added the following factors: people's prevailing sense of confusion and chaos at the time of the outbreak, their need to readjust to their new situation and their concerns for their families. The participants' emotional responses and sense of threat stemmed from their concerns for their own health and that of their loved ones, their worries about employment, their difficulties in staying home with their children and spouses, and the problems posed by working at home. These findings are in line with findings of previous studies conducted during the COVID-19 outbreak pointing to a variety of concerns among research participants: health anxiety, personal health, threat to loved ones, and risk control, employment, virus spread and economic and societal consequences [21].

Another major source of fear regarding COVID-19 was the perceived risk of infection among loved ones. This fear can be mitigated by providing the general public with clear information about the risks and by taking (additional) steps to protect vulnerable groups at risk of infection [21].

This study has several limitations. Given that the survey was conducted in the fourth week of the virus outbreak in Israel, it paints an immediate and initial picture of the reactions of the lay public to COVID-19. With the spread of the virus, the behavioral guidelines are constantly changing. Therefore, research should continue to explore psychological and emotional responses among the lay public across time. Second, the use of a mix-methods approach limits the ability to generalize our results to a wider population and to make claims about directionality.

\section{Declarations}

\section{Ethics approval and consent to participate:}


Before the research began, the Ethics Committee of Bar-llan University approved the study (Authorization No. 032003). All study data were stored safely, and only the researcher had access to the data. All personal data were coded, so that the identities of the participants remained confidential.

\section{Consent for publication:}

The participants gave their consent to participate in the study and were informed that any publications based on the data would not include identifying information.

\section{Availability of data and materials:}

The authors have the research data, which is available upon request.

\section{Competing interests:}

The authors declare that they have no competing interests.

\section{Funding:}

None

\section{Authors' contributions:}

IL contributed to the research design, writing the study protocol and organizing the study, coordinated the data collection, carried out the initial analysis, drafted the initial manuscript and approved the final submitted manuscript. SSA contributed to the study design and organization, participated in the data collection, reviewed the manuscript, and approved the final submitted manuscript. All authors read and approved the final version of the manuscript.

\section{Acknowledgements:}

Not applicable

\section{References}

1. Qiu J, Shen B, Zhao M, Wang Z, Xie B, Xu Y. A nationwide survey of psychological distress among Chinese people in the COVID-19 epidemic: implications and policy recommendations. Gen Psychiat. 2020;33:e100213.

2. Xiang YT. Timely mental health care for the 2019 novel coronavirus outbreak is urgently needed. Lancet Psychiatry. 2020;7:228-9. 
3. Hall RCW, Chapman MJ. The 1995 Kikwit Ebola outbreak: Lessons hospitals and physicians can apply to future viral epidemics. Gen Hosp Psychiat. 2008;30:446-52.

4. Rubin GJ, Potts HWW, Michie S. The impact of communications about swine flu (influenza A H1N1v) on public responses to the outbreak: Results from 36 national telephone surveys in the UK. Health Technol Assess. 2010;14:183-266.

5. Van Bortel T. Psychosocial effects of an Ebola outbreak at individual, community and international levels. Bull World Health Organ. 2016;94:210-4.

6. Leung GM. The impact of community psychological responses on outbreak control for severe acute respiratory syndrome in Hong Kong. J Epidemiol Commun Health. 2003;57:857-63.

7. Sim K. Psychosocial and coping responses within the community health care setting towards a national outbreak of an infectious disease. J Psychosom Res. 2010;68:195-202.

8. Mohammed A, Sheikh TL, Gidado S, Poggensee G, Nguku P, Olayinka A, Ohuabunwo C, Waziri N, Shuaib F, Adeyemi J, Uzoma O. An evaluation of psychological distress and social support of survivors and contacts of Ebola virus disease infection and their relatives in Lagos, Nigeria: a cross sectional study - 2014. BMC Public Health. 2015;15:824.

9. Wang C, Pan R, Wan X, Tan Y, Xu L, Ho CS, Ho RC. Immediate psychological responses and associated factors during the initial stage of the 2019 coronavirus disease (COVID-19) epidemic among the general population in china. Int J Environ Res Public Health. 2020;17:1729.

10. Israel Ministry of Health. The Novel Coronavirus. https://govextra.gov.il/ministry-ofhealth/corona/corona-virus-en/. Assessed 24 Apr 2020.

11. Jiang F, Deng L, Zhang L, Cai Y, Cheung CW, Xia Z. Review of the clinical characteristics of coronavirus disease 2019 (COVID-19). J Gen Intern Med. 2020. https://doi.org/10.1007/s11606-02005762-w.

12. Klausner Z, Fattal E, Hirsch E, Shapira SC. A single holiday was the turning point of the COVID-19 policy of Israel. medRxiv. 2020. https://doi.org/10.1101/2020.03.26.20044412.

13. $\mathrm{Li} \mathrm{H}$, Chen $X$, Huang $H$. The novel coronavirus outbreak: what can be learned from China in public reporting? Global Health Res Policy. 2020;5:1-3.

14. Werner P, Goldberg S, Mandel S, Korczyn AD. Gender differences in lay persons' beliefs and knowledge about Alzheimer's disease (AD): A national representative study of Israeli adults. Arch Gerontol Geriatr. 2013;56:400-4.

15. Patton MQ. Two decades of developments in qualitative inquiry a personal, experiential perspective. Qual Soc Work. 2002;1:261-83.

16. Creswell JW, Poth CN. Qualitative inquiry research methods: Choosing among five approaches. 4th ed. Los Angeles: Sage; 2018.

17. Brinkman S, Kvale S, Interviews. Learning the craft of qualitative research interviewing. 3rd ed. Los Angeles: Sage; 2015. 
18. Mohammed A, Sheikh TL, Gidado S, Abdus-Salam IA, Adeyemi J, Olayinka A, Ohuabunwo C, Victor OO, Nguku P, Rasheed EA, Doherty F. Psychiatric treatment of a health care worker after infection with Ebola virus in Lagos, Nigeria. Am J Psychiatry. 2015b;172:222-4.

19. Wu P, Fang Y, Guan Z, Fan B, Kong J, Yao Z, Liu X, Fuller CJ, Susser E, Lu J, Hoven CW. The psychological impact of the SARS epidemic on hospital employees in China: exposure, risk perception, and altruistic acceptance of risk. Can J Psychiat. 2009;54:302-11.

20. Cinelli M, Quattrociocchi W, Galeazzi A, Valensise CM, Brugnoli E, Schmidt AL, Zola P, Zollo F, Scala A. The covid-19 social media infodemic. arXiv. 2020. arXiv:2003.05004.

21. Mertens G, Gerritsen L, Salemink E, Engelhard I. Fear of the coronavirus (COVID-19): Predictors in an online study conducted in March 2020. PsyArXiv. 2020. https://doi.org/10.31234/osf.io/2p57j.

22. Peng EYC, Lee MB, Tsai ST, Yang CC, Morisky DE, Tsai LT, Weng YL, Lyu SY. Population-based postcrisis psychological distress: an example from the SARS outbreak in Taiwan. J Formos Med Asso. 2010;109:524-32.

23. Suryawanshi R, More V. A study of effect of Corona Virus Covid-19 and lock down on human psychology of Pune City region. SIPN. 2020;40:984-94.

24. Holman EA, Garfin DR, Silver RC. Media's role in broadcasting acute stress following the Boston Marathon bombings. Proc Natl Acad Sci. 2014;111:93-8.

25. Garfin DR, Silver RC, Holman EA. The novel coronavirus (COVID-2019) outbreak: Amplification of public health consequences by media exposure. Health Psychol. 2020. https://doi.org/10.1037/hea0000875.

26. Rigotti T, De Cuyper N, Sekiguchi T. The corona crisis: What can we learn from earlier studies in applied psychology? Editorial. Appl Psychol Int Rev. 2020. https://iaapjournals.onlinelibrary.wiley.com/pbassets/assets/14640597/APIR_Virtual_Issue_COVID_19_Editorial-1585819191813.pdf. Accessed 24 Apr 2020.

\section{Figures}


$60.00 \%$

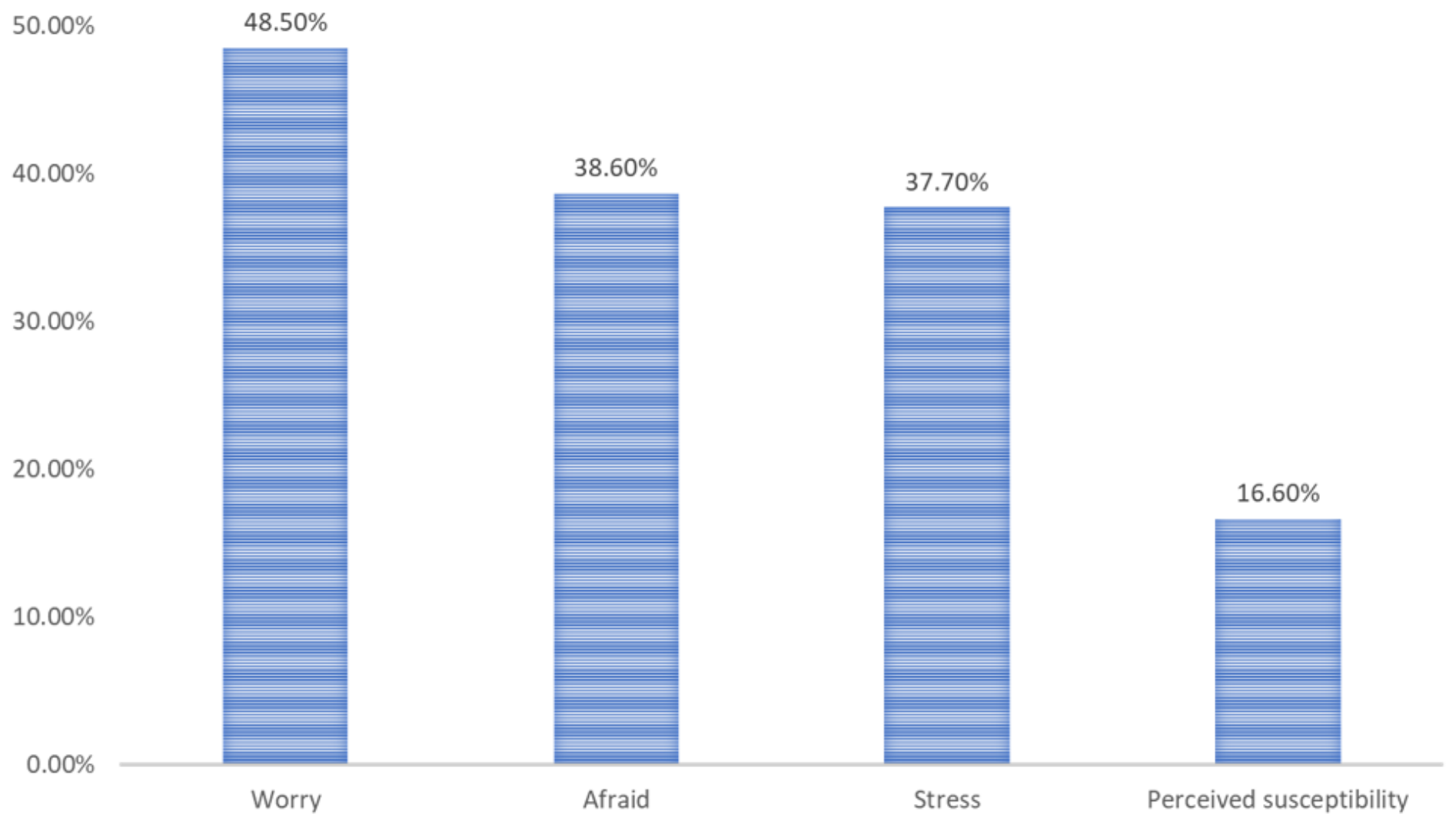

Figure 1

Level of emotional reactions and perceived susceptibility among study participants $(n=1,407)$

\section{Supplementary Files}

This is a list of supplementary files associated with this preprint. Click to download.

- Appendix1.docx 